\title{
El libro antiguo en la red \\ o El contacto de los extremos
}

\author{
Manuel José Pedraza Gracia \\ Universidad de Zaragoza
}

\subsection{Resumen}

Se reflexiona sobre las sedes dedicadas al libro antiguo en Internet. Se examinan especialmente las sedes de Internet dedicadas a la investigación en libro antiguo e historia del libro, al libro antiguo en las bibliotecas, a los recursos para el tratamiento del material antiguo y las páginas web de libreros anticuarios y bibliófilos. Se destacan las carencias detectadas. (Autor)

Palabras clave: Libro antiguo. Libro raro. Internet. Bibliotecas. Librería anticuaria. Bibliofilia.

\subsection{Abstract}

Web sites devoted to old books are discussed, with special attention to those related to research on rare books and the history of the book and printing. Web sites produced by the libraries, resources for the rare materials' cataloguer, web sites dealed with antiquarian booksellers and book collectors are examined. The shortages are indicated. (Author)

Keywords: Old books. Rare books. Rare materials. Internet. Libraries. Antiquarian bookshops. Bibliophily. Book collectors.

\section{Introducción}

A simple vista parece que en ambos extremos del mundo de la investigación sobre la información se han de situar los estudios sobre el libro antiguo (investigación aparentemente vetusta y rancia) y los trabajos sobre la red (investigación mucho más moderna y avanzada); y, aunque solamente en el curso cronológico de los acontecimientos sea cierto que esa situación en la hipotética línea cronológica es aceptable, esta ubicación no supone que sean ámbitos que no se puedan relacionar, de tal suerte que el mundo del libro antiguo no pueda encontrar algunos beneficios simbióticos en su relación con las (hoy ya talluditas) tecnologías. Las bibliotecas se han situado en un nivel de beneficio simbiótico que se puede califi- 


\section{2}

car de sobresaliente en el potencial del acceso a la información por medio de la red mediante, por ejemplo, el acceso a recursos de ayuda para el tratamiento técnico en línea. A la par, la red ha permitido a las bibliotecas romper sus muros (independientemente del material que fuesen) y llegar a cualquier lugar con la información que poseen. Y, no sólo las bibliotecas, los archivos, los museos y otros centros de Información se hallan en la red reclamando nuevos usuarios de la información existente en ellos. De la misma manera, el libro antiguo, en ocasiones objeto único, al que hay que ir a visitar con veneración, el muy local y muy aristocrático libro antiguo, ha encontrado en la red, accesible desde cualquier lugar, democrática y globalizadora, un abanico inmenso de posibilidades que han desbordado las previsiones más optimistas. En este trabajo se pretende analizar la situación del libro antiguo en la red desde todas las perspectivas que le afectan pretendiendo ofrecer más una panorámica de lo que no se encuentra en Internet (y podría estar), especialmente en nuestro entorno, que de lo que se encuentra con facilidad, incidiendo para ello en la calidad de los recursos existentes. Para este fin, ante todo, es necesario analizar, aunque sea de forma somera, qué se entiende por libro antiguo en las diversas facetas en las que éste puede encontrarse.

El libro antiguo desde una perspectiva académica es el objeto que se estudia desde diversas ciencias que pueden quedar englobadas en la bibliografía-bibliología. En palabras de Paul Otlet (1934, p. 9) "Necesitamos ahora no solamente de bibliografía, descripción de los libros, sino de bibliología [documentología)", esto es, "Ciencia general que abarque el conjunto sistemático clasificado de los datos relativos a la producción, la conservación, la circulación y la utilización de los escritos y los documentos de toda especie", siendo su primer fin "analizar, generalizar, clasificar, sintetizar los datos adquiridos en los entornos del libro y al mismo tiempo promover investigaciones nuevas destinadas sobre todo a profundizar el porqué teórico de ciertas prácticas de la experiencia". Por tanto, el libro antiguo, es el objeto de estudio de esas ciencias y, por consiguiente, existen una serie de investigadores que hacen del estudio del libro en general y del libro antiguo en particular su mundo. El libro antiguo es también, en buena parte, el componente del fondo antiguo, raro o precioso de una biblioteca, esto es, el libro impreso producido manualmente. Se ha establecido la frontera cronológica en el año 1801, pero que en opinión de muchos debería o bien trasladarse hasta un par de décadas más tarde, o bien permanecer en el mundo menos estricto del concepto. Por extensión, se incluyen dentro de este fondo antiguo, raro o precioso de las bibliotecas los libros manuscritos y, en consecuencia, los libros manuscritos antiguos. Debe precisarse que el concepto de libro raro o libro precioso no está sometido a la dictadura de la cronología, por tanto, no se pueden identificar de manera plena estas definiciones con el concepto de libro antiguo sin estrías y chirridos, cuyo pulimento no corresponde a este trabajo. Dentro de la biblioteca está, como el resto de

Scire. $8: 2$ (jul.-dic. 2002) 71-90. 
la colección, sujeto al proceso documental. El libro antiguo es, en ocasiones, el patrimonio de todos. Resulta ser, entre otros documentos, objeto del patrimonio bibliográfico de una comunidad o de un estado. Concepto este, fundamentalmente jurídico, que acentúa más la protección y custodia que el uso y difusión. Pero, en el parecer de muchos, esta perspectiva confiere al libro antiguo la propiedad de pasar a formar parte del tesoro común de un pueblo que integra lo que a ese pueblo le ha interesado y lo que ha producido intelectualmente, también, en efecto, lo que los antecesores consideraron de suficiente importancia como para plasmarlo en libro. Es, por tanto, el eje vertebral de la herencia intelectual (científica, literaria, artística e ideológica) de una comunidad. El libro antiguo es un objeto de valor económico contrastado, lo que conduce a que se trate de un objeto de comercio y, como tal, esté sometido a las leyes de la oferta y demanda (y no se debe olvidar que se trata de un bien escaso). Existen, desde que el hombre tomó consciencia del valor del libro, unos canales comerciales de este libro-producto. El libro antiguo es también un objeto artístico, atractivo, no sólo por su contenido figurativo, sino también por la belleza y el cuidado en la producción, es un libro-arte. De este libro se realizan facsímiles que tienen como objeto la socialización de ese objeto valioso contenedor de arte y arte en sí mismo. Éste es el mundo de la bibliofilia, que cada vez, conforme crece el nivel económico medio, se democratiza más alcanzando a un mayor número de personas interesadas en coleccionar libro antiguo, raro o precioso, artístico, o de poseer facsímiles, bien sea por el placer que esto puede ocasionar (la mera posesión), bien sea por el placer de leerlos, bien sea por la inversión que pueda suponer. Pero, el libro antiguo es también, sobre todo,

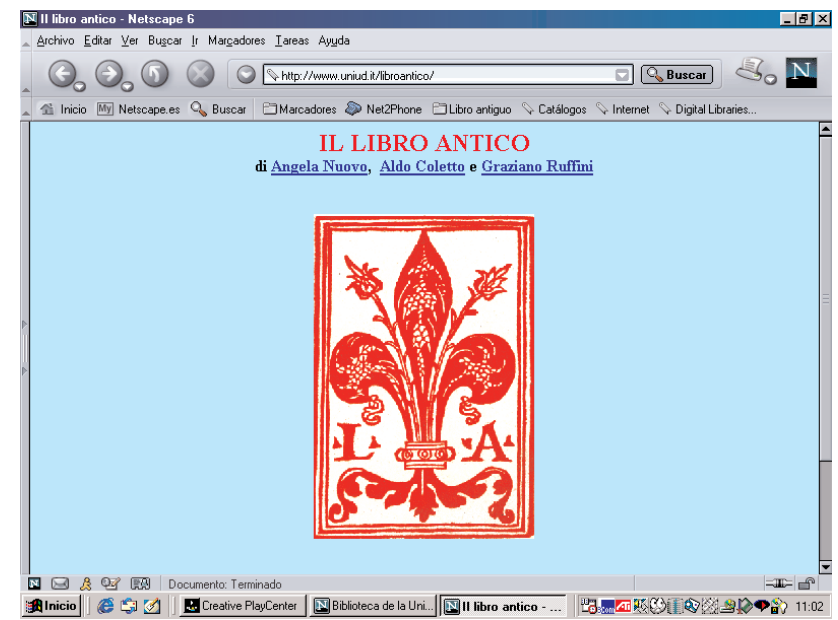

Figura 1. Il libro antico

Scire. $8: 2$ (jul.-dic. 2002) 71-90. 
documento, fuente esencial para el estudio de otras ciencias y técnicas: el derecho, la historia, la medicina, la física, la literatura, la ingeniería... Son las fuentes que permiten aproximarse de forma más directa a los conocimientos concretos del pasado, fundamento del conocimiento presente.

Ninguno de estos apartados en los que se divide aquí el estudio del libro antiguo ha de considerarse un compartimento estanco; todos ellos guardan relaciones entre sí. Lógicamente, el objeto es siempre el mismo, el libro antiguo, el mismo libro, o mejor el mismo tipo de libro, interesa al investigador del objeto (bien sea desde la perspectiva histórica, material, estructural o bibliográfica), al bibliotecario en cuyo fondo se encuentra, al político cultural que debe tenerlo en cuenta a la hora de establecer el patrimonio común y perseguir su mejora y ampliación, al bibliófilo que espera encontrar diferencias apreciables con el ejemplar que posee él mismo o al investigador de la materia a la que hace referencia el libro, cuyo contenido aclara un aspecto preciso en la evolución histórica de la ciencia que estudia.

Aunque el libro antiguo puede ser apreciado desde muchas perspectivas distintas, como se ha visto, y pueda tener un tratamiento variado, aunque general, suele tener dentro de Internet, debido a la potencialidad de la estructura hipertextual de la red, o bien un tratamiento combinado o bien muy particular. En la red encontraremos, sin lugar a dudas, magnificas descripciones de fondos antiguos y, también ofertas de libros impresionantes a la venta, junto con otros muchos recursos que inciden de muy diversa manera en su propio objeto, el libro antiguo. Hay magníficas páginas repletas de enlaces, cientos de ellos, muchas veces los mismos enlaces que se encuentran en páginas de intereses distintos. Excelentes

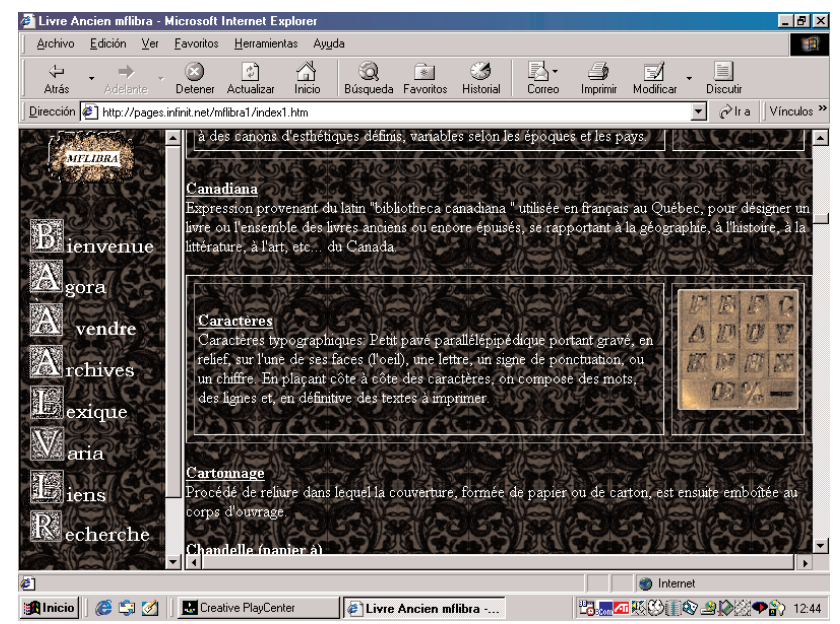

Figura 2. Diccionario sobre el libro antiguo en MFLIBRA

Scire. $8: 2$ (jul.-dic. 2002) 71-90. 
páginas dedicadas a enlaces sobre el libro antiguo son: la de la Canadian Bookbinders and Book Artists Guild titulada Others Sites of Book Arts Interest (http://www.cbbag.ca/links.html), la de la Association of College and Research Libraries, Rare Books and Manuscripts Section titulada Directory of Web Resources for the Rare Materials Cataloger (http://www.library.upenn.edu/ipc/ rarecat.html), la de la Universidad de Oxford dedicadas a su proyecto Early Printed Books Project titulada Resources (http://www.lib.ox.ac.uk/icc/resource.html) y la italiana titulada Il libro antico creada por Angela Nuovo, Aldo Coletto y Graziano Ruffini (http://www.uniud.it/libroantico), entre otras muchas. Como puede apreciarse, proceden de intereses distintos, a pesar de lo cual no es difícil encontrar en ellas los mismos enlaces agrupados en bloques muy similares. La complejidad que presenta el estudio del libro antiguo queda puesta de manifiesto en la propia red cuando se considera que es preciso incluir los numerosos diccionarios y vocabularios sobre el tema que se encuentran en ella para servir de apoyo a los interesados en ese mundo. Como ejemplo, se ha seleccionado el diccionario incluido en la web MFLIBRA (http://pages.infinit.net/mflibra1/index 1.html) por tratarse de un de un diccionario de confección cooperativa, para lo que utiliza las facilidades de comunicación que ofrece la propia red.

\section{El libro antiguo, objeto de estudio}

El libro antiguo se puede analizar como objeto desde una perspectiva histórica, desde una perspectiva exclusivamente bibliográfico-material, desde una perspectiva estructural o desde una perspectiva bibliográfico-sintética.

La perspectiva histórica es quizás la primera que debe abordarse cuando se trata de analizar objetos históricos. La contextualización del objeto histórico en su época es trascendental cuando se trata de estudiar un objeto decorativo o artístico, pero el libro es algo más que eso, el libro no sólo trasmite sensaciones, sino que también aporta, con mayor claridad que cualquier otro objeto histórico, las sensibilidades, la ideología, los intereses, el conocimiento de un autor y de su época. En la red se localizan numerosas historias del libro, que facilitan esa contextualización. No suele tratarse de trabajos de gran profundidad, pero permiten una buena aproximación. Un buen ejemplo de lo apuntado, entre los muchos que existen incluidos en otras obras o independientes, se encuentra en sendos artículos de Richard W. Clement sobre la historia del libro manuscrito e impreso reunidos en ORB: The Online Reference Book for Medieval Studies (http://orb.rhodes.edu/encyclop/culture/books/bookdex.html).

El libro antiguo y moderno es el resultado de la aplicación de tecnologías específicas en momentos cronológicos concretos, por tanto, cada época tiene un desarrollo tecnológico y un libro fabricado con esa tecnología. El análisis bibliográfico-material interpretando las tecnologías utilizadas para la confección del

Scire. $8: 2$ (jul.-dic. 2002) 71-90. 
libro, las materias primas usadas, la calidad, las características y el manipulado de las mismas, los recursos técnicos empleados, los procesos realizados para su confección, la identificación de los responsables de todos estos parámetros son imprescindibles para el análisis del libro antiguo, ya que una vez conocidos sus efectos en el producto final, se puede ubicar el libro dentro de ese mundo tecnológico y productivo y relacionarlo con otros libros y otros ejemplares con los que comparte las mismas características o de los que se distingue por diferir en ellas. Las webs dedicadas al estudio de la evolución de las tecnologías y los procesos del libro y de las materias primas son muy numerosas y en ocasiones muy relacionadas entre sí y, como no podía ser de otra manera, con las que se dedican a la historia del libro. Destacan especialmente entre las páginas webs que se ocupan de estos temas los museos de la imprenta, bien sea museos reales como el Musée de l'Imprimerie de Lyon, (http://www.mairie-lyon.fr/sp/), bien sea museos virtuales como el creado en Portugal a partir especialmente de imágenes (http://www.imultimedia.pt/museuvirtpress/).

Es, también, fácil encontrar páginas web que se destinan al estudio de las materias primas del libro impreso y manuscrito, por ejemplo, las dedicadas al papel y a su fabricación como la de la International Association of Paper Historians (http://www.paperistory.org), a la tinta para la escritura y caligrafía como, Iron Gall Ink de Elmer Eusman (http://www.knaw.nl/ecpa/ink/hatml/ink.html) o a la encuadernación como Bookbinding and the Conservation of Books de Matt T. Roberts y Don Etherington (http://palimpsest.stanford.edu/don/don.html), entre otros aspectos que son tratados por recursos en la red y otras muchas páginas web. En éstas se

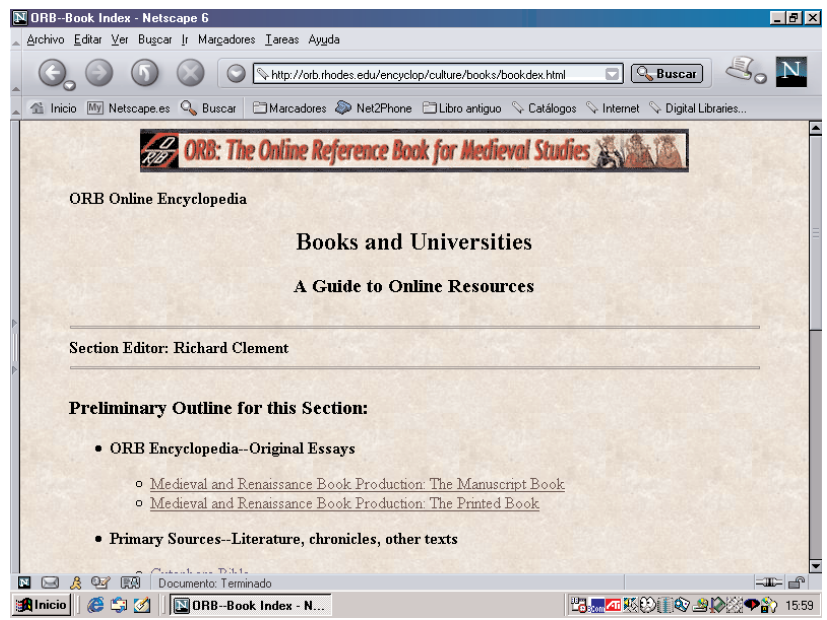

Fig. 3. Artículos de R. W. Clement para ORB: the Online Reference Book for Medieval Studies

Scire. $8: 2$ (jul.-dic. 2002) 71-90. 
pueden encontrar descripciones muy pormenorizadas de las tecnologías utilizadas en la confección de las materias primas en diversos momentos, de la evolución de los útiles, las herramientas y las máquinas, de las diversas calidades del producto, de la identificación de las mismas, de los procesos necesarios para su fabricación y el orden de los mismos... Estas páginas encuentran en la red un soporte muy adecuado debido a que suelen utilizar numerosos recursos gráficos con el fin de precisar la información que ofrecen.

A la tipografía y al diseño de tipos se dedican numerosas páginas en la red y, en menor medida, las hay dedicadas al grabado y a la explicación de las diversas técnicas de estampación. Especialmente la tipografía y la escritura se ha convertido en un elemento de gran interés entre los usuarios de la red. No es difícil hallar páginas web dedicadas a la caligrafía, a sus útiles y sus técnicas y hay numerosas páginas webs que recogen los métodos de impresión y los juegos tipográficos, si bien, en ambos casos se hace referencia tanto a los procedimientos tipos de letra y juegos tipográficos más antiguos como a los más modernos. Como ejemplo, puede consultarse la página Planet Typography que incluye, además de los apartados dedicados a la tipografía uno dedicado a la historia de la imprenta de los que, como se ha dicho, hay tantos en la red (http://www.planet-typography.com)

Por tanto, la vertiente técnica de apoyo a los análisis bibliográfico-materiales está perfectamente representada en la red por páginas diversas de temáticas muy variadas. Hay que apuntar, no obstante, que no se hallan webs españolas dedicadas a estas temáticas. A pesar de las posibilidades gráficas que ofrece la

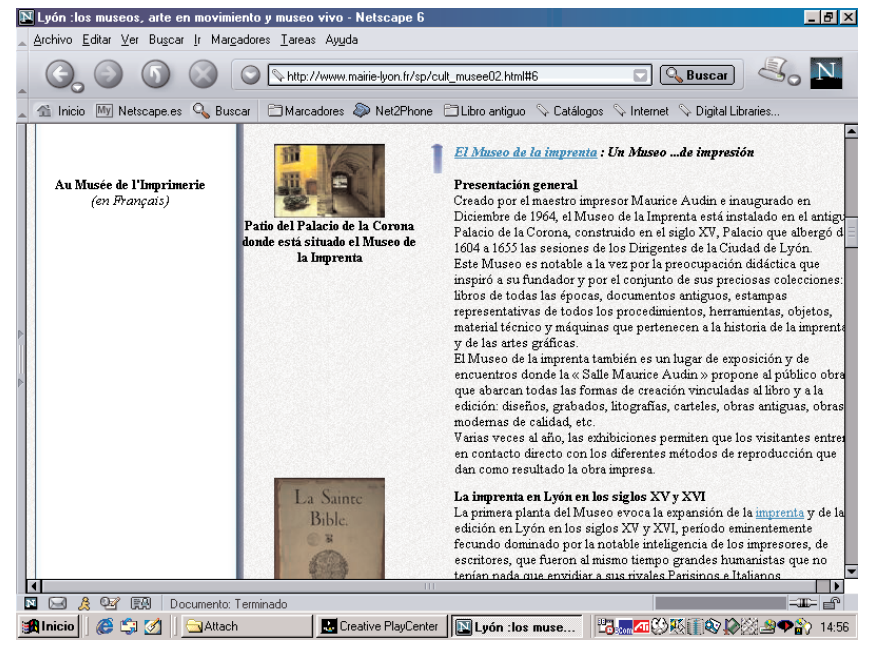

Figura 4. Museo de la imprenta de Lyon

Scire. $8: 2$ (jul.-dic. 2002) 71-90. 
red, tampoco hay análisis materiales, siquiera parciales, de períodos, zonas, impresores, libros, etc. Se carece, por ejemplo, a todos niveles, de webs que se dediquen a recopilar los recursos tipográficos de un impresor, tanto figurativos como propiamente tipográficos, o a establecer las diferencias y similitudes de las tipografías utilizadas en una zona o en un período, o a los usos tipográficos de un impresor o casa tipográfica, o a determinar las características del papel, o a (re)crear repertorios de marcas y contramarcas de agua... Es decir, a crear recursos informativos que coadyuven a los análisis materiales del libro. Hay que hacer excepción de la preciosa página web creada en la Universidad de Barcelona dedicada a la recopilación de una base de datos que agrupa marcas de impresores, libreros y editores de todo el mundo (http://eclipsi.bib.ub.es/imp/impcat.html).

Los contenidos estructurales del libro no llegan siquiera a obtener el mismo grado de dedicación en Internet. Estos contenidos son el resultado de la aplicación de mecanismos ideológicos específicos en momentos cronológicos concretos. Cada época tiene unas ideologías que se trasmiten a los componentes estructurales del libro (Simón Díaz, 1983). Sobre la estructura formal del libro es difícil hallar información siquiera de referencia, o si se halla, ésta se encuentra muy diluida en el conjunto, más armónico, de la sociología del (mundo) impreso frente a la sociología del (mundo) manuscrito. La estructura del libro antiguo evolucionó en comparación con los elementos técnicos mucho más y más rápidamente. El análisis de esta estructura facilita la datación de las obras, relaciona la obra y el autor con otros autores con los patrocinadores o mecenas de las obras, ubica la obra en el ámbito de lo legal y lo religioso... Se trata, junto con la legislación

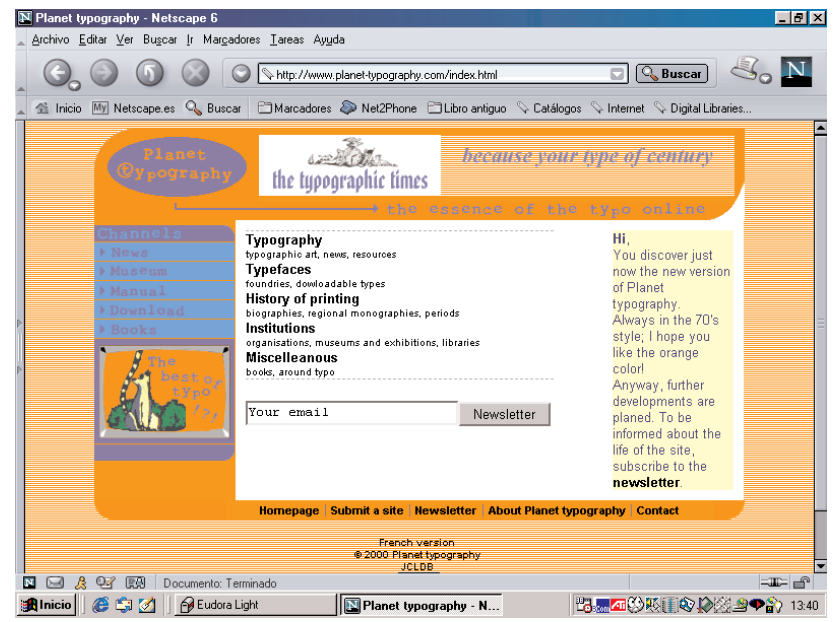

Figura 5. Planet Typography, una de las muchas webs dedicadas a la tipografía

Scire. 8 : 2 (jul.-dic. 2002) 71-90. 
antigua de libro e imprenta, la censura y lo censurado, de uno de las facetas del libro antiguo no han entrado todavía en la red. El porqué de esta dicotomía entre los aspectos bibliográfico-materiales y los bibliográfico-estructurales quizás haya que buscarlo en el muy diferente interés gráfico de ambas facetas, en la diferente profundidad de las mismas y, seguramente, en la diferente formación requerida para su estudio. En cualquiera de los casos, el análisis de las estructuras formales del libro no se constituye en apartado de interés para las webs dedicadas al libro antiguo. Difícilmente se encuentran noticias sobre los textos legales y literarios que visten al libro antiguo y que lo ubican en el momento (social, político, religioso...) de su aparición.

La bibliografía sintética, esto es, la recopilación y registro de las notas características que identifican un documento (Montaner, 1999, p. 11), en este caso antiguo, es la última de las facetas que puede interesar al investigador del libro y, seguramente la que resulta más evidente. En otro lugar ya se trató de forma monográfica de este tema (Pedraza, 1999) analizando las tremendas posibilidades que ofrece la red para la realización del trabajo bibliográfico retrospectivo. Poco se puede añadir desde entonces sobre este aspecto, ya que apenas ha evolucionado la implantación de bibliografías retrospectivas en la red. Han surgido, sin embargo, algunas webs, generalmente procedentes de exposiciones, que se dedican al estudio de los grandes impresores que incluyen no solo la biografía de los mismos y el entorno social e histórico en el que debieron trabajar, sino también las obras que produjeron. Son interesantes las webs dedicadas a Aldo Manuccio titulada In aedibus Aldi: the legacy of Aldus Manutius and his press (http://library.byu.edu/ aldi-

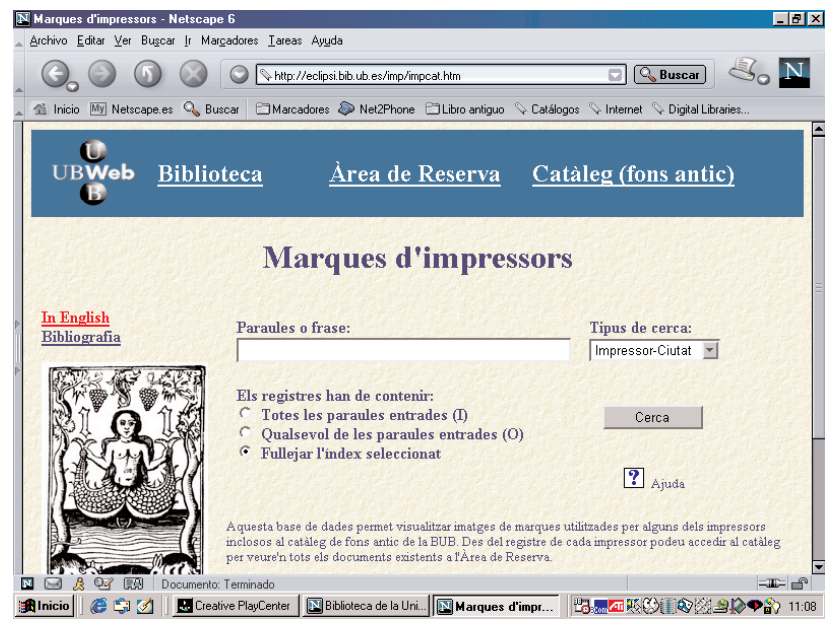

Figura 6. Base de datos sobre marcas de impresores y editores creada en la Universidad de Barcelona

Scire. $8: 2$ (jul.-dic. 2002) 71-90. 
ne/), o a Jacques Estienne titulada Catalogue Jacques Estienne 1713 (http://www.chez.com/bibliophile/catalogue_jacques_estienne.html) o la muy interesante Menasseh Ben Israel: Overzicht van de collectie, página web dedicada a los impresos hebreos realizados en Holanda (http://www.uba.nl/nl/collecties/ rosenthalia/menasseh/backer). Por el mismo procedimiento (de la preexistente exposición) han aparecido webs dedicadas al estudio de determinados autores y sus obras incluyendo las ediciones conocidas de las mismas. Sirva de ejemplo la dedicada a Dante Alighieri en la web Renaissance Dante in Print (1472-1629) (http://www.nd.edu/ itelnet/Dante/).

Por lo que respecta a la existencia en la red de bibliografías locales, regionales o nacionales no se ha mejorado prácticamente nada en los últimos años. En nuestro ámbito cultural hay que destacar Philobiblon creado por Paul Faulhaber y su equipo en la Universidad de Berkeley destinado a recoger los textos antiguos producidos en la Península Ibérica y que se divide en tres grupos: textos en español, textos en gallego y portugués y textos en catalán (http://sunsite.berkeley.edu/ Philobiblon/phhm.html). Existe también una modesta aportación en Aragón que se ha denominado EBRA (Esbozo de Bibliografía Retrospectiva Aragonesa) cuya intención es reunir en una base de datos la producción bibliográfica de Aragón desde 1475 hasta 1950 y que hasta la fecha incluye algo más de 8.000 registros procedentes de las tipobibliografías clásicas aragonesas publicadas en papel. Aspira a ser, además, una bibliografía cooperativa o, realizada de forma cooperativa, ya que lo que se pretende es la que la introducción de nuevos ítems se realice utilizando la propia red y por parte de cualquier investigador que, teniendo noticia

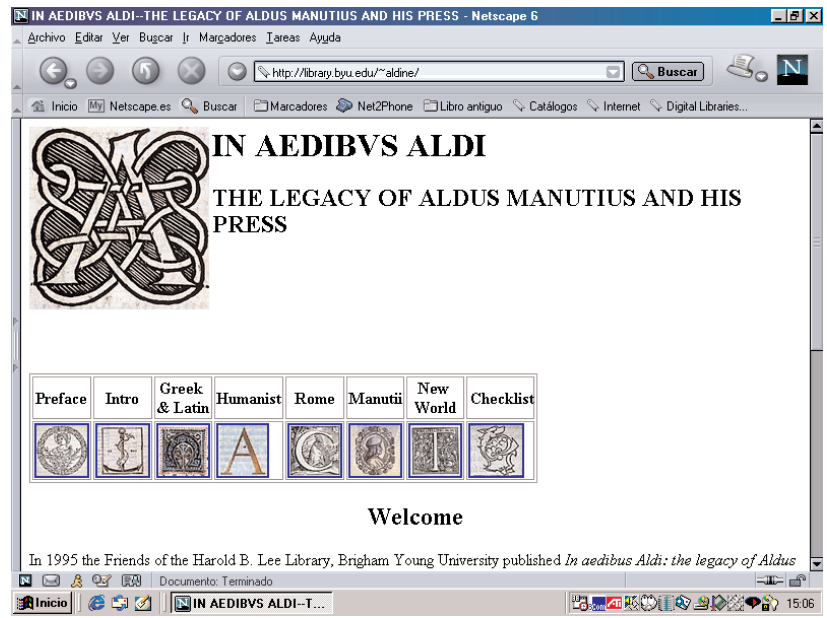

Figura 7. In aedibus Aldi, dedicada al impresor Aldo Manuccio y a su producción

Scire. $8: 2$ (jul.-dic. 2002) 71-90. 
de la existencia de un libro no incluido en $E B R A$ desee aportar su registro a la base de datos. Esfuerzos similares se están realizando para la creación de bibliografías más concretas, sobre temas específicos, pero no se trata en ningún caso de crear nuevas bibliografías retrospectivas, cuyo principal objetivo sea el libro antiguo. En consecuencia, desde una perspectiva general, existe un diverso nivel de tratamiento en la red cuando se habla de la historia del libro, de su evolución técnica y de su evolución ideológica en detrimento de ésta, verdadero desierto. En el ámbito espacial que nos afecta, la carencia de trabajos con profundidad en la red es más aparente. Faltan, webs dedicadas exclusivamente a la historia del libro español, a sus estructuras materiales y también, webs que expliquen el cómo y el porqué de todos estos textos que visten al libro antiguo español y que tienen una importancia capital. Por lo que hace referencia a la bibliografía retrospectiv,a continúa apreciándose la carencia de proyectos, que seguramente deben ser avalados por los organismos administrativos, tendentes a dar a conocer la producción bibliográfica de las comunidades que administran.

\section{El fondo antiguo de la biblioteca}

El fondo antiguo de la biblioteca es un fondo que no suele introducir problemas en la gestión bibliotecaria, salvo los derivados de su préstamo y su preservación. El fondo antiguo de las bibliotecas españolas está, como todas ellas, generalmente inmerso en una economía de subsistencia que lo suele convertir en un compartimento estanco dentro del centro. El libro antiguo en la biblioteca será más o menos solicitado, expuesto, protegido, pero lo más frecuente es que nadie tenga

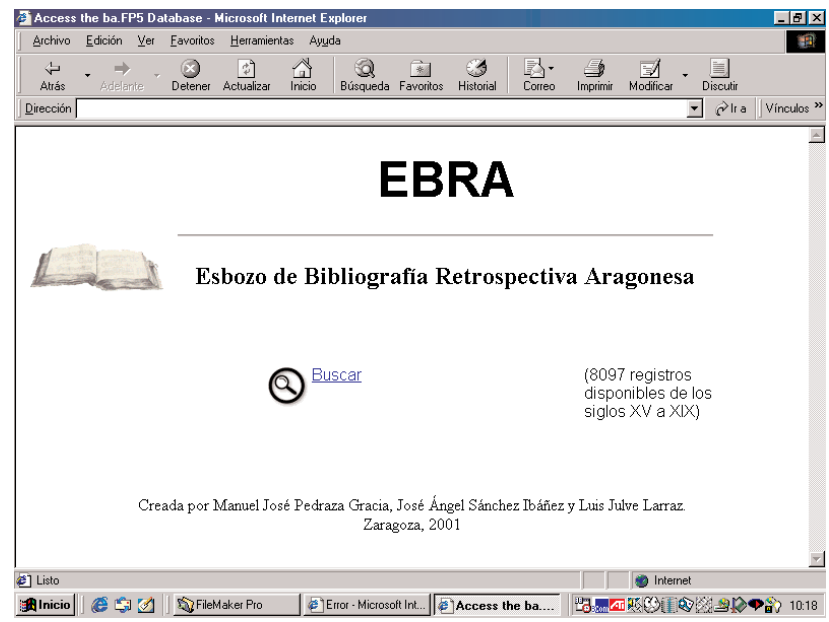

Figura 8. EBRA: esbozo de bibliografía retrospectiva aragonesa creada en la Universidad de Zaragoza

Scire. $8: 2$ (jul.-dic. 2002) 71-90. 
que volver a tratar el fondo antiguo de una biblioteca y son raros los casos en los que las posibilidades económicas permiten su selección y su adquisición. De este panorama hay que extraer, lógicamente, las bibliotecas que tienen competencias e intereses específicos en la preservación, custodia y adquisición de patrimonio bibliográfico (Marsá, 1999). La adquisición del libro antiguo suele seguir las vías conocidas, pero invertidas. El libro antiguo es adquirido por la biblioteca más por donación o por depósito que por compra. Las librerías especializadas en libro antiguo no suelen tener a las bibliotecas como principal cliente, más bien se trata de clientes residuales y problemáticos. Por esta misma causa es preferible tratarlas cuando se hable del mundo que realmente adquiere libros antiguos, el bibliófilo. La ausencia práctica de adquisición es la causa principal, especialmente en España, de la inexistencia de catálogos de bibliotecas en la red que ofrezcan especial interés por su contenido en libros antiguos, dado que no se suele proceder a la conversión retrospectiva de este fondo cuyo catálogo fue publicado en momentos pretéritos o se halla inmerso en los catálogos colectivos creados antes de la aparición de Internet. Bien es cierto que este fenómeno ha sido suplido por la existencia del Catálogo Colectivo de Patrimonio Bibliográfico del que se tratará más adelante, lo que ofrece, sin embargo, la ventaja de la obtención por parte del usuario que lo utiliza de un panorama general de los fondos existentes en todo el país.

En Internet, pueden encontrarse normas completas para el tratamiento bibliográfico de los libros antiguos. De esta manera, se obtienen ayudas en línea a la hora de realizar los trabajos descriptivos pertinentes, como es el caso de las DCRM (Descriptive Cataloging of Rare Materials), herederas directas de las DCRB (Descriptive Cataloging of Rare Books), incluyendo listas de reglas optativas, discusiones sobre problemas detectados y ejemplos. Estas normas, listas y foros pueden consultarse en la página del Comité para Normas Bibliográficas de la Association of College and Research Libraries, Rare Books and Manuscripts Section (http://www.lib.byu.edu/ catalog/people/rlm/bsc). También, se encuentran con facilidad numerosas herramientas de apoyo que ayudan a la identificación del libro antiguo de cara a su tratamiento. En la red es fácil encontrar listados de nombres latinos con imprenta entre los que pueden citarse la página de la Association of College and Research Libraries, Rare Books and Manuscripts Section (http://www.lib.byu.edu/ catalog/people/rlm/latin/ names.htm\#top) dedicada al tema Latin Place Names; o las ya mencionadas dedicadas a las casas impresoras más importantes o a determinados autores. No obstante, cuando se hace referencia a las listas de nombres latinos de ciudades con imprenta, por ejemplo, se aprecia que en ninguna de las tres listas consultadas en la red — la ya mencionada de la sección de la Association of College and Research Libraries, la del Orbis Latinus online que sigue la obra de Graesse publicada en 1909 ni el listado utilizado por el Cathedral Libraries Catalogue- quedan bien paradas las

Scire. 8 : 2 (jul.-dic. 2002) 71-90. 
ciudades españolas (en ninguna de las tres figura la forma latina Caesaraugusta, por ejemplo, utilizada en la imprenta incunable zaragozana) (Cf. Mantecón, 1973 o Urso, 1990). Es también bastante evidente la falta de normas españolas en la red. Tampoco encontramos en la red ninguna página web dedicada a los impresores que han trabajado en España, listados de impresos y razones sociales, tan útiles de cara a la identificación de los impresores, por ejemplo.

Por lo que respecta a la recuperación y difusión de los fondos antiguos, algunas bibliotecas extranjeras suelen incluir en sus webs excelentes imágenes y registros de propios fondos antiguos. Basta para percibir esta situación navegar en una página creada en la Universidad de Idaho que tiene como objeto incluir las sedes web de todo el mundo (en torno a 4.700) que describen manuscritos, archivos, libros raros, fotografías históricas y otras fuentes primarias llamada Repositories of Primary Sources (http://www.uidaho.edu/specialcollections/Other.Repositories.html). No es todavía frecuente, la presencia de reproducciones íntegras de libros o documentos antiguos de forma facsimilar. En muchos casos se encuentran reproducciones completas de obras concretas de forma individual como el Bestiario de Aberdeen (http://www.clues.abdn.ac.uk :8080/besttest/firstpag.html) o colecciones de documentos gráficos e impresos recientes que tratan de forma sistemática un tema concreto, como American Memory: Historical Collections for the National Digital Library (http://lcweb2.loc.gov/ammem/ammem.html) creado por la Library of Congress, pero no se encuentran listas sistemáticas de facsímiles de libro antiguo de una biblioteca, siquiera matizadas por ser la obra de un autor, la producción de una

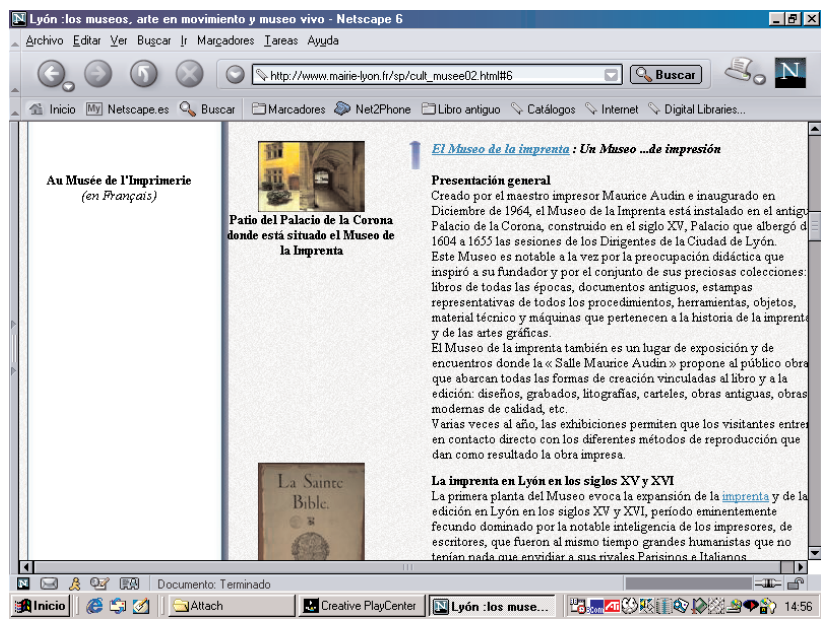

Figura 10. Edición facsímil electrónica en la red del Bestiario de Aberdeen

Scire. $8: 2$ (jul.-dic. 2002) 71-90. 
localidad, de un país o de un período cronológico, a pesar de la existencia de un número muy importante de proyectos de digitalización de fondos antiguos.

Una serie de pautas relativas al préstamo de los materiales antiguos para ser expuestos y de su custodia preparadas por la Association of College and Research Libraries puede encontrarse en versiones íntegras en la web (http://www.ala.org/ acrl/guides). Las webs empeñadas en labores de preservación son de las que resal$\tan$ en la red, se pueden localizar webs dedicadas a explicar el tratamiento para pequeñas restauraciones, un buen ejemplo es Reparación de libros bajo parámetros de conservación, versión al español de un manual de pequeña restauración realizado por la Biblioteca Estatal de Alaska, aunque hay que decir que se trata de un manual destinado más al libro moderno que al antiguo (http://www.lib.msu.edi/ drewes/RepairManual.html) o sobre recursos para la conservación, Conservation On Line (http://palimpsest.stanford.edu), entre otras muchas. Estas webs son normalmente productos de valor añadido de las casas comerciales dedicadas a la preservación y a la restauración de los materiales antiguos.

Las posibilidades que ofrece la red para mantener productos informativos que faciliten las labores que se realizan en la biblioteca con el fondo antiguo son inmensas. Aunque no siempre mantengan unos niveles de utilidad aceptable, existen en la red productos que facilitan la identificación del libro antiguo, el tratamiento, la identificación de los lugares de publicación, la identificación de ediciones y variantes, identificación de faltas, panorámicas de grabados o de tipografías, etc. Hay, en nuestro entorno también una ausencia de normativa y de ayuda en línea, con ejemplos, aplicaciones concretas y elementos de discusión sobre la normativa que ayuden a su modificación... Además existe la carencia de los catálogos de los fondos antiguos existentes en gran número de bibliotecas españolas en la red. Pero lo que se echa de menos especialmente es la realización de facsímiles de fondos antiguos tendentes tanto a la identificación de otros ejemplares y de variantes como a su disfrute visual.

\section{El patrimonio de todos}

En España se ha creado uno de los recursos informativos en la red más interesantes de los que se pueden encontrar en la actualidad, el Catálogo Colectivo de Patrimonio Bibliográfico Español (http://www.mcu.es/ccpb), pero no se hallan bajo su sombra otra serie de instrumentos que deberían haber surgido bajo su paraguas como catálogos colectivos regionales de bibliotecas con fondo antiguo. La inclusión de este recurso en la red es la consecuencia del procedimiento utilizado para redactar el catálogo desde las comunidades autónomas. Pero parece que se ha renunciado a la formación de catálogos colectivos regionales, a pesar de que las administraciones autonómicas participan en su elaboración, según el artículo 52.1 de la ley de Patrimonio y de que las propias bibliotecas participan-

Scire. $8: 2$ (jul.-dic. 2002) 71-90. 
tes, es decir, aquellas cuyos fondos se incluyen renuncian también a los registros producidos con estos fondos. La existencia de este único catálogo, precisamente produce una paradoja que se antoja a efectos de planificación incomprensible: las bibliotecas que han sido completamente catalogadas para introducir su fondo antiguo en el Catálogo Colectivo carecen de un catálogo de su propio fondo antiguo derivado del mismo. Ni que decir tiene que esto implicará tarde o temprano o la realización de un doble trabajo o, lo que sería peor, a la adquisición de registros confeccionados tomando como base las obras existentes en la biblioteca que adquiere los registros. Este mismo aspecto llevado a su nivel autonómico es más grave ya que se está renunciando a un elemento de control de patrimonio en el nivel regional imprescindible por parte de los responsables administrativos del patrimonio que colaboran en la elaboración del catálogo colectivo nacional.

Existen otros catálogos colectivos en países de nuestro entorno que, aunque tienen carácter general, permiten la recuperación del fondo antiguo existente en las bibliotecas de esos países. Dos buenos ejemplos son Catalogue collectif de France (http://www.ccfr.bnf.fr/rnbcd_visu/accl.html) y el catálogo colectivo italiano llamado Indice $S B N$ creado por el Istituto Centrale per il Catalogo Unico (http://opac.sbn.it/cgi-bin). Pero en estos países existen numerosos catálogos de lfondo antiguo de bibliotecas individuales accesibles desde Internet.

La ubicación del Catálogo Colectivo del Patrimonio Bibliográfico Español en Internet, con objeto de que pudiese ser consultado en línea por los encargados de redactar los nuevos asientos y, especialmente, para contrastar que la obra cuyos datos se han de introducir se encuentre ya incluida en el catálogo, no ha

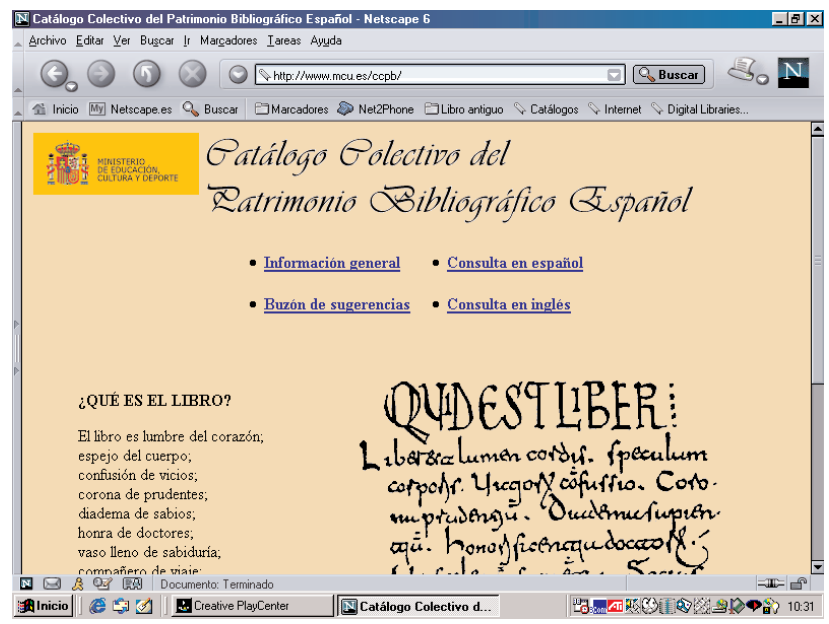

Figura 11. Catálogo Colectivo del Patrimonio Bibliográfico Español

Scire. $8: 2$ (jul.-dic. 2002) 71-90. 
procurado recursos paralelos de ayuda a la redacción de los asientos de fondo antiguo: ISBD(A), MARC aplicado a fondo antiguo, autoridades para fondo antiguo, listados de nombres latinos de ciudades con imprenta, listados de impresores por ciudades, abreviaturas en los primeros impresos, tipos arcaicos... (todos ellos en línea) que servirían de ayuda no sólo a los redactores del catálogo sino también a todos los que pudiesen trabajar con él; o, si fuese preciso, solicitar ayuda para la redacción cooperativa del catálogo. También ha velado la posibilidad de que la política cultural sobre el patrimonio bibliográfico llegue a los propietarios de ese patrimonio, los ciudadanos. Los políticos en quienes los ciudadanos han legado esa responsabilidad cumplen con ella únicamente cooperando con el Catálogo Colectivo Nacional, obviando la responsabilidad de crear el catálogo autonómico propio, que debería ser accesible también desde la red y que debería incluir los esfuerzos realizados en aumentar el patrimonio (en libro antiguo), indicando las nuevas adquisiciones y los lugares en los que se podrían consultar esos fondos, así como su mantenimiento y acondicionamiento, indicando los documentos restaurados o puestos en valor.

\section{El deseo del bibliófilo y la invitación del librero-anticuario}

El coleccionismo de libros, antiguos o no, es uno de los aspectos que más se han desarrollado en Internet, donde han adquirido mucha fuerza los foros de debate sobre el libro, las webs creadas por los libreros de anticuario y por los bibliófilos. El impulso fundamental dado al mundo del libro antiguo en la Internet, como objeto de compraventa y colección, ha sido realizado por las librerías anticuarias. En mayor o menor medida las librerías anticuarias y las casas de subastas han percibido que Internet es el perfecto escaparate para mostrar sus productos al mayor número de compradores posible. Un buen ejemplo de web de librería anticuaria es la de la librería zaragozana Hesperia (http://hesperialibros.com). Los catálogos de anticuario circulan por la red y las peticiones de libros se resuelven mediante correos electrónicos. Se crean también páginas especializadas desde las asociaciones de libreros como la española Libri (http://www.libris.es). También las editoriales especializadas en editar facsímiles han utilizado la red para dar a conocer sus producciones, el libro reproducido para colección, buscando sus clientes en la red y ofreciendo incluso sus obras por suscripción. En España existen algunas de estas editoriales que se sirven de la red, por ejemplo, M. Moleiro Editor que publica en la red una oferta de reproducciones de beatos en una página específica (http://www.beato-de-liebana.com).

Debido a la explosión de este mercado globalizado, han surgido los portales del libro, sedes comerciales especializadas en servicios destinados a los bibliófilos generalmente enlazadas con otras sedes que mantienen múltiples recursos sobre el libro antiguo y que no suelen tener carácter comercial. Pueden consul-

Scire. $8: 2$ (jul.-dic. 2002) 71-90. 
tarse, por ejemplo, el más general Portal del Libro (http://www.portaldellibro. com) o el más específico Portal del libro antiguo en castellano (http://www.libroantiguo.com). Se establecen mecanismos para poder distribuir en Internet desideratas de libros concretos mediante formularios que se distribuyen por diversas librerías y que contestan indicando el estado de conservación y las características especiales del ejemplar que se ofrece y su precio.

Los bibliófilos también han desarrollado sus propios recursos web muy similares a los de los propios libreros anticuarios, es decir, con numerosos enlaces a recursos históricos, a diccionarios y enciclopedias temáticas, a catálogos de librerías anticuarias, a bibliotecas con importantes fondos antiguos, a asociaciones de bibliófilos, a foros de debate especializados, a revistas sobre libro antiguo, a museos del papel o de la imprenta, etc. Pero una de las aportaciones más interesantes ha sido el desarrollo de los tablones de anuncios, esto es, lugares en la red en los que los bibliófilos anuncian libros en venta y solicitan libros específicos que desearían comprar, y que sirven también para completar obras descabaladas. Por una parte, estas páginas son desarrolladas por las asociaciones de bibliófilos como la internacional Antiquarian Booksellers Association International (http://www.aba.org.uk) o la española Concentus libri (http://www.concentus.es). Por otra parte, surgen páginas, resultado de esfuerzos individuales o de determinadas instituciones dedicadas a favorecer el gusto por el libro antiguo, páginas de "faq's" como Your Old Books (http:// www.rbms.nd.edu/yob.html) o a definir aspectos dudosos del mundo del libro como Quelques définitions de bibliophilie... (http://www.chez.com/ bibliophile/definition.html). En España las librerías anti-

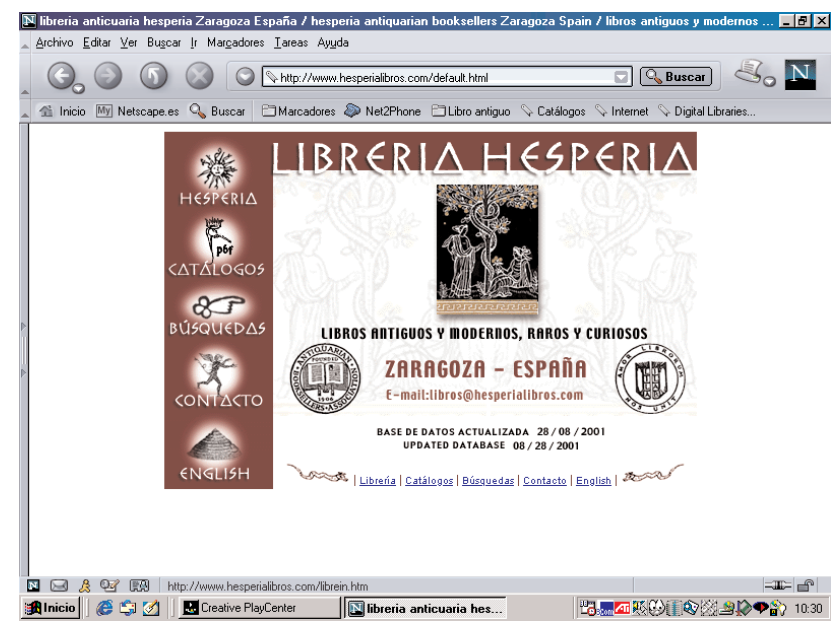

Figura 12. Página web de la librería zaragozana Hesperia

Scire. $8: 2$ (jul.-dic. 2002) 71-90. 

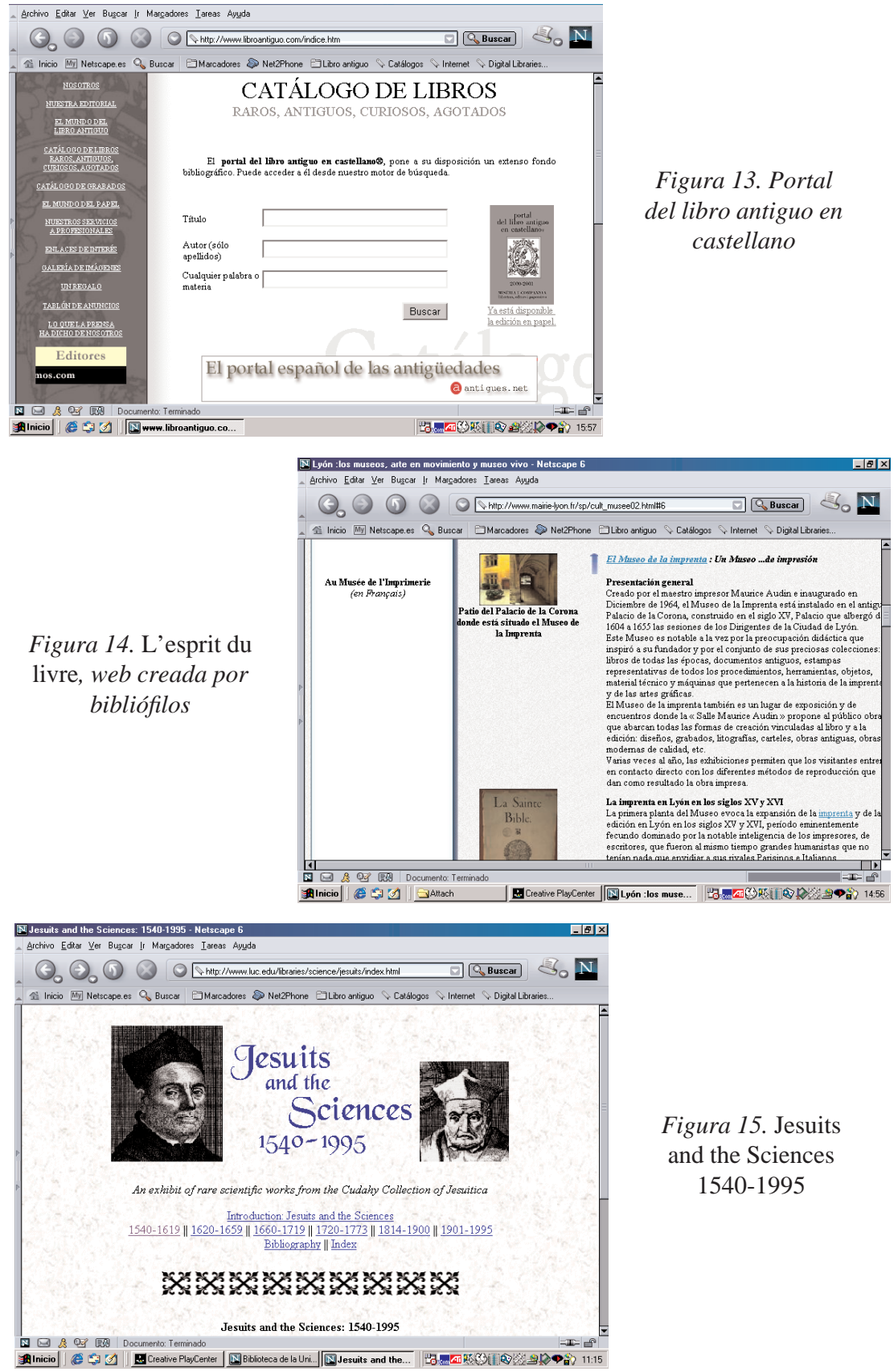

Figura 15. Jesuits and the Sciences 1540-1995 
cuarias y, en menor medida, los bibliófilos se incorporan paulatinamente a la red ofreciendo aquéllas servicios en Internet como valor añadido a su propio servicio y éstos información y lugares de encuentro virtuales. Aún cuando no está completamente desarrollado este campo en nuestro país es, sin embargo, el que mayor expectativa de desarrollo tiene en estos momentos, debido especialmente al incremento del comercio del libro antiguo y a la democratización de la bibliofilia y el coleccionismo.

\section{La fuente de información y de investigación}

El libro es también documento que informa de las circunstancias en las que una determinada ciencia se encuentra en el momento en el que fue escrito, es, desde esta perspectiva, la instantánea de la ciencia en cuestión. Es, en consecuencia, elemento imprescindible a la hora de establecer la evolución de cualquier ciencia. A pesar de la inmensidad de datos que se precisan por las respectivas ciencias y lo densa que podría ser esta información ubicada en Internet, la red es también en este extremo un páramo. Es difícil encontrar sedes webs creadas por especialistas en una ciencia que se dediquen a la producción bibliográfica antigua sobre la ciencia en cuestión. Los especialistas en historia de la literatura han desarrollado mejor que ningún otro grupo de investigadores especialistas recursos en la red. Baste recordar Parnaseo, creado en la Universidad de Valencia por el equipo del profesor Canet (http://parnaseo.uv.es) o el mencionado Philobiblon. Se trata, sin duda, de sedes web de gran interés para los investigadores del libro antiguo.

Además, existen en la red otros intentos de digitalización, que han tenido mayor o menor fortuna. Es el caso, por ejemplo, del proyecto Dioscórides (http://www.ucm.es/BUMC/diosc), llevado a cabo en la Universidad Complutense por equipos de investigación en historia de la medicina. Hay también trabajos especializados procedentes de exposiciones virtuales, por ejemplo, El legado de las matemáticas: de Euclides a Newton: los genios a través de sus libros (http://euler.us.es/ libros/index.html) o de exposiciones reales como Jesuits and the Sciences 1540-1995: an Exhibit of Rare Scientific Works from the Cudahy Collection of Jesuitica (http://www.luc.edu/libraries/sciences/jesuits/ index.html).

\section{Conclusiones}

El libro antiguo se encuentra muy presente en Internet, ya que son muchas las sedes web que bien directa o bien indirectamente hacen referencia al mundo del libro antiguo en sus diversas facetas. No obstante, esa información es frecuentemente redundante. Resulta complejo encontrar información de calidad en la red, ya que el número suele ocultar en este caso la superficialidad en el tratamiento de los temas. Hay facetas del libro antiguo tratadas en numerosas páginas web apor-

Scire. $8: 2$ (jul.-dic. 2002) 71-90. 
tando muy pocas cosas nuevas unas con respecto a las otras. La historia del libro o la historia de las técnicas son buenos ejemplos de lo mencionado. Otras facetas, sin embargo, son ignoradas en Internet: los estudios sobre estructura bibliográfica, por ejemplo. Cada vez más surgen nuevos recursos tendentes a la ayuda en línea para las bibliotecas, y éstas difunden sus fondos antiguos mediante la red a la par que se crean grandes catálogos colectivos nacionales. Pero la vertiente que más se ha desarrollado en los últimos tiempos ha sido la relacionada con el comercio del libro antiguo, la bibliofilia y el coleccionismo. Si se traslada el objetivo de estudio a España, se aprecia que, más que sedes dedicadas al libro antiguo, hay que desarrollar todavía recursos concretos que faciliten el trabajo de los estudiosos, las bibliotecas, los bibliófilos y los investigadores. Ffaltan recursos bibliográficos retrospectivos en la red dedicados a ámbitos geográfico-administrativos más concentrados que el nacional y prácticamente no existen colecciones digitalizadas. El desarrollo del mundo del comercio del libro y el coleccionismo se ha revelado como un campo en expansión que se ha demostrado altamente rentable.

En suma, queda más por hacer sobre el libro antiguo en la red que lo que se ha hecho, puesto que hay campos prácticamente vírgenes y existe la tendencia a que en los campos tratados se produzca la ausencia de calidad y exhaustividad. Hay, sin embargo, esfuerzos concretos, como los mencionados más arriba, que han de ser tenidos muy en cuenta a la hora de seguir su evolución, ya que reflejan un trabajo de calidad que puede servir de guía para futuros trabajos.

\section{Referencias}

Mantecón Navasal, José Ignacio (1973). Índice de nombres latinos de ciudades con imprenta: 1448-1825. México: Universidad Nacional Autónoma, 1973.

Marsá Vila, María (1999). El fondo antiguo en la biblioteca. Gijón: Trea, 1999.

Montaner Frutos, Alberto (1999). Prontuario de bibliografía: pautas para la realización de descripciones, citas y repertorios. Gijón: Trea, 1999.

Otlet, Paul (1996). El tratado de documentación de Paul Otlet: el libro sobre el libro: teoría y práctica, traducción de María Dolores Ayuso García. Murcia: Universidad de Murcia, 1996.

Pedraza Gracia, Manuel José (1999). La bibliografía retrospectiva en la WWW: un nuevo horizonte para una ciencia clásica. // Scire: representación y organización del conocimiento. 5:2 (1999) 75-89.

Simón Díaz, José (1983). El libro español antiguo: Análisis de su estructura. Kassel: Reichenberger, 1983.

Urso, T. (1990). Toponomastica bibliografica: guida ai nomini dei luoghi di stampa fino al 1799. Florencia: Leo S. Olschki, 1990. 